\title{
Teatro, literatura y cultura del exilio republicano español en la Unión
} Soviética (1939-1949)

Manuel Aznar soler

\section{Citer ce document / Cite this document :}

Aznar soler Manuel. Teatro, literatura y cultura del exilio republicano español en la Unión Soviética (1939-1949). In: Exils et migrations ibériques au XXe siècle, n6, 1999. 60 ans d'exil républicain : des écrivains espagnols entre mémoire et oubli. pp. 61-76;

doi : https://doi.org/10.3406/emixx.1999.1003

https://www.persee.fr/doc/emixx_1245-2300_1999_num_2_6_1003

Fichier pdf généré le 28/08/2018 


\title{
Teatro, literatura y cultura del exilio republicano español en la Unión Soviética (1939-1949)
}

\author{
Manuel Aznar Soler \\ Universitat Autònoma de Barcelona
}

Para Rosa Gálvez

La característica que singulariza al exilio republicano español de 1939 en la antigua Unión de Repúblicas Socialistas Soviéticas (URSS) es su militancia no exclusiva pero sí mayoritariamente comunista. Cuantitativamente fue minoritario respecto al de otros países americanos (México, Argentina) o europeos (Francia), pero la calidad de la obra literaria, intelectual y artística de algunos de nuestros exiliados republicanos en la antigua Unión Soviética no merece en absoluto el olvido casi completo en que se halla ${ }^{1}$. Intentar una primera aproximación a su historia, prácticamente inédita como tema de investigación entre nosotros, constituye el objetivo fundamental de estas páginas.

\section{Un exilio reducido y selectivo}

Parece lógico que, si México y la Unión Soviética fueron los únicos países que - cada uno a su manera - ayudaron a la República española durante la guerra civil, fueran también los espacios más generosos a la hora de acoger a nuestros vencidos republicanos. Pero si la inteligente política del general Lázaro Cárdenas abrió las puertas de México a la pluralidad política de nuestro exilio republicano ${ }^{2}$, la actitud de la URSS de Stalin fue muy

1 "En total se ha calculado que en 1967 había en la Unión Soviética alrededor de tres mil emigrados", afirma Vicente Lloréns en "La emigración republicana de 1939", en AAVV, El exilio español de 1939, coordinación de José Luis Abellán. Madrid, Taurus, 1976, tomo I, p. 116.

2 Manuel Aznar Soler, "Cultura y literatura del exilio republicano español de 1939 en México". Taifa, 4 (otoño de 1997), p. 15-40, número monográfico sobre "El exilio español en México (1939-1977)". 
opuesta. En rigor, la URSS sólo se interesó a partir de 1939 por los refugiados que eran militantes del Partido Comunista de España : dirigentes políticos (José Díaz, Jesús Hernández, Dolores Ibárruri, Vicente Uribe), jefes militares (Antonio Cordón, Valentín González, Enrique Líster, Juan Modesto, Manuel Tagüeña), arquitectos (Luis Lacasa, Manuel Sánchez Arcas), científicos (Federico Molero, Juan Planelles), escritores y artistas (Alberto Sánchez, César Arconada, Eusebio Cimorra, Julio Mateu, Isidoro Rodríguez Acevedo y José Luis Salado, entre otros) o traductores (Agustín Argüelles Manso, José Laín Entralgo).

Así, desde que el 10 de abril de 1939 zarpase el buque "Smolny" del puerto francés de El Havre rumbo a Leningrado, varios barcos soviéticos transportaron a la URSS a exiliados republicanos españoles ${ }^{3}$. La suma total, sin embargo, en ningún caso sobrepasó la cifra de dos mil personas ${ }^{4}$. Ahora bien, si nuestro exilio republicano en la URSS fue en 1939 reducido y políticamente muy selectivo, no debemos olvidar que durante la guerra civil ya habían viajado a ella otros colectivos ${ }^{5}$ y que, por ejemplo, varios miles de niños habían sido acogidos durante la guerra civil con sus maestros respectivos. Unos "niños de la guerra" que, como el director de escena

3 Javier Rubio, La emigración de la guerra civil de 1936-1939. Historia del éxodo que se produce con el fin de la II República española. Madrid, Librería Editorial San Martín, 1977, tomo primero, p. 200.

4 Javier Rubio, ob. cit., p. 201. Por su parte, Daniel Arasa dedica el capítulo II de su libro Los españoles de Stalin a "El exilio español en la URSS" (Barcelona, Editorial Vorágine, 1993, p. 25-55).

5 Antonio Vilanova clasifica en cuatro grupos (niños y maestros; marinos; aviadores y políticos) a esos "emigrantes" en su libro Los olvidados. Los exilados españoles en la segunda guerra mundial. París, Ruedo Ibérico, 1969, p. 465-477.

${ }^{6}$ Sobre el tema pueden consultarse los libros de Enrique Zafra, Rosalia Crego y Carmen Heredia, Los niños españoles evacuados a la URSS (Madrid, Ediciones de la Torre, 1989), y el de Alicia Alted Vigil y Encarna Nicolás, Los niños de la guerra de España y la Unión Soviética: de la evacuación al retorno (Madrid, Fundación Largo Caballero, 1999). La propia Alicia Alted Vigil es autora de "Jeunes filles évacuées vers l'URSS en 1939: le retour", en AAVV, L'émigration: le retour, études rassemblées par Rose Duroux et Alain Montandon. Clermont-Fcrrand, Université Blaise Pascal, Centre de Recherches sur les Littératures Modernes et Contemporaines (CRLMC), 1999, p. 545-559. 
Ángel Gutiérrez ${ }^{7}$, estudiaron e iniciaron su trayectoria escénica en la URSS de Stalin.

\section{Un problema de fuentes}

No conozco hasta la fecha ningún estudio monográfico sobre el teatro, la literatura y cultura del exilio republicano español de 1939 en la Unión Soviética. Pero este vacío bibliográfico no se explica ya únicamente por las razones políticas obvias a que lo condenó el franquismo pues, desaparecidas éstas, sigue vigente durante nuestro actual proceso democrático. Y es que, como objeto de investigación, este tema nos plantea ante todo un problema de fuentes. En efecto, no es fácil en la mayoría de los casos encontrar los libros o revistas en que colaboraron nuestros exiliados republicanos que, por otra parte y a diferencia del exilio en América, "experimentaron la barrera del idioma ${ }^{81} \mathrm{y}$, por lo tanto, un proceso de integración en la sociedad socialista soviética acaso aún más complejo y difícil. Por otra parte, está claro que, aunque la edición no se rigiera en una sociedad socialista por la ley de la oferta y la demanda propia del mercado capitalista, la publicación de libros o revistas en lengua castellana era, lógicamente, un verdadero problema por el carácter minoritario de su público potencial. Además, el contexto histórico internacional determinó que, como en Francia, las necesidades de la guerra fueran mucho más perentorias y a ellas se tuvieron que supeditar todas las actividades culturales.

En efecto, desde la firma en Moscú del pacto germano-soviético (23 de agosto de 1939) a la invasión de la URSS por el ejército nazi (22 de junio de

7 Ángel Gutiérrez Ramírez, catedrático de Interpretación en la Real Escuela Superior de Arte Dramático de Madrid, dirige actualmente el Teatro de Cámara de Madrid. Evacuado en 1937 desde Asturias a la URSS cuando tenía seis años, estudió Dirección Escénica en el Instituto Estatal de Arte Teatral Lunatcharski de Moscú. Antes de regresar a España en 1974, fue durante dieciocho años catedrático de Interpretación y Dirección del Instituto del Teatro de Moscú y dirigió más de cuarenta obras, entre las que cabe destacar en $1963 \mathrm{La}$ casa de Bernarda Alba, de García Lorca, con escenografia de Alberto Sánchez, puesta en escena en el Teatro Stanislavski de Moscú. Sobre su trayectoria escénica y su concepto teatral puede consultarse "Éste es Ángel Gutiérrez" y "Con Ángel Gutiérrez" (entrevista), en Primer Acto, 210-211 (septiembre-diciembre de 1985), p. 131 y 132-141, respectivamente.

${ }^{8}$ V. Lloréns, ob. cit., p. 117. 
1941) y la victoria de las tropas aliadas en la segunda guerra mundial, la dureza de la vida cotidiana en la URSS ${ }^{9}$ y las adversas condiciones políticas relegaron a un plano muy secundario las actividades culturales de nuestro exilio republicano, aunque las emisiones en lengua castellana desde la capital soviética de Radio Moscú y las de Radio España Independiente, la "Pirenaica", se escuchaban entonces en medio mundo ${ }^{10}$. Los nombres de Santiago de Paul Nelken - hijo de la escritora Margarita Nelken - o de Rubén Ruiz Ibárruri, hijo de Pasionaria, simbolizan a todos los combatientes de nuestro exilio republicano caídos en las filas del ejército soviético contra el nazismo durante la segunda guerra mundial ${ }^{11}$. En rigor, las escasas actividades culturales del exilio republicano pueden reconstruirse a partir de 1940 a través de las noticias que aparecen en el semanario España Popular, editado por el Partido Comunista de España en México. Las colaboraciones de José Luis Salado ${ }^{12}$ o de Isidoro Acevedo ${ }^{13}$, por ejemplo, vienen a informar mínimamente a unos lectores comunistas para quienes la Unión Soviética constituye entonces la esperanza real de un paraíso posible ${ }^{14}$. Y también a través de la publicación en este semanario de algunos manifiestos ${ }^{15}$, podemos constatar la expresión de esa solidaridad de nuestra

9 Joan Estruch Tobella nos proporciona datos al respecto en El PCE en la clandestinidad (1939-1956). Madrid, Siglo XXI, 1982, p. 61-62.

${ }^{10}$ Luis Galán, que desde diciembre de 1944 hasta 1954 formó parte de la redacción española de Radio Moscú y desde 1954 pasó a residir en Bucarest, en donde trabajó cerca de veinte años en Radio España Independiente (la Pirenaica), es autor de un interesante libro titulado Después de todo. Recuerdos de un periodista de la Pirenaica (Barcelona, Anthropos, colección Memoria Rota - 15, 1988), prologado por Manuel Vázquez Montalbán. Por su parte, Eusebio Cimorra fue durante muchos años locutor de las emisiones en lengua castellana de Radio Moscú.

11 Antonio Vilanova, "Los combatientes", en ob. cit., p. 479-500.

12 Entre las colaboraciones de José Luis Salado en España Popular anotemos, por ejemplo, "Escenarios de Moscú", 13 (9 de mayo de 1940), p. 7, y "La cultura española en la URSS", 61 (4 de julio de 1941), p. 2.

13 Isidoro Acevedo, "iTodos unidos!". España Popular, 332 (7 de febrero de 1947), p. 3.

14 "Se constituye en México la "Comisión Española de Ayuda a la URSS". España Popular, 117 (15 de enero de 1943), p. 3.

15 "En su último número, el semanario Literatura y Arte, órgano de la Unión de escritores soviéticos, publica en lugar destacado una carta a los literatos de la URSS firmada por los prosistas y poetas españoles Rafael Alberti, Blanco Amor, María Teresa León, Rafael 
intelectualidad republicana de todos los colores políticos con una URSS en guerra :
Al cumplirse en esta fecha victoriosa los tres años de vuestra gloriosa guerra, que es la nuestra y la de todos los pueblos amantes de la libertad, los españoles republicanos de profesión intelectual en el exilio queremos enviar de nuevo a nuestros compañeros soviéticos [...] el testimonio de nuestra amistad, de nuestra esperanza, de nuestra fe en el triunfo final $^{16}$.

Naturalmente, las relaciones políticas y culturales entre el exilio republicano español y el pueblo soviético son muy estrechas en aquel contexto histórico. En la mayoría de los casos, las crónicas reflejan la presencia de la cultura española en la URSS ${ }^{17}$, sea la música ${ }^{18}$, el $\operatorname{arte}^{19}$ o la literatura, en donde Lope de Vega, Antonio Machado (boletín de Francia),

Dieste y otros que ha producido en los medios intelectuales de Moscú una excelente impresión", según se informa en "Los literatos españoles saludan a los colegas soviéticos". España Popular, 151 (27 de agosto de 1943), p. 2.

${ }^{16}$ El manifiesto, fechado en México D. F. el 22 de junio de 1944, está firmado, entre otros, por Manuel Andújar, Arana, Arderíus, Max Aub, Bergamín, Pere Calders, Josep Carner, Gallegos Rocafull, Francisco Giner de los Ríos, Herrera Petere, Ímaz, Izcaray, Jarnés, Larrea, León Felipe, Masip, Prados, Rejano, Samblancat, Sánchez Barbudo o Sánchez Vázquez, lo que prueba el amplio espectro frentepopular de nuestra intelectualidad republicana exiliada. Reproduzco este manifiesto, publicado en España Popular, 196 (30 de junio de 1944), p. 5, asi como otros dos - titulados "Saludo a la Unión Soviética de los republicanos españoles en México", 319 (8 de noviembre de 1946), p. 3, y "Saludo de los intelectuales españoles a la Unión Soviética", 372 (14 de noviembre de 1947), p. 2 - en mi libro Materiales para una historia del exilio literario republicano de 1939: Manifiestos, textos, polémicas y documentos. Sant Cugat del Vallès, Cop d'Idees-Grupo de Estudios del Exilio Literario (en prensa).

${ }^{17}$ K. Grigoriev, "La cultura española en la URSS". España Popular, 302 (12 de julio de 1946), p. 4.

18 Fernando Cardona, "Música española en la Unión Soviética". España Popular, 224 (12 de enero de 1945), p. 5.

19 Celso Amieva, "El arte español en la URSS". España Popular, 979 (15 de noviembre de 1967), p. 6. 
García Lorca, Valle-Inclán o Rafael Alberti ${ }^{20}$ constituyen las referencias más reiteradas. No olvidemos por otra parte la existencia de un muy activo hispanismo soviético que simboliza, por ejemplo, Fédor Kelin, autor de numerosas traducciones a la lengua rusa ${ }^{21}$. Muy pocas veces, sin embargo, hallamos en España Popular la voz colectiva del propio exilio republicano español en la URSS ${ }^{22}$. Pero también es cierto que no sólo en España Popular podemos rastrear la huella teatral, literaria y cultural de nuestro exilio republicano en la URSS : otros órganos de expresión como el Boletín de la Unión de Intelectuales Españoles de Francia (París), Independencia (París), Cultura y Democracia (París), Nuestro Tiempo (México), Cuadernos de Cultura (Madrid-México), Boletín de la Unión de Intelectuales Españoles de México (México), Nuestras Ideas (Bruselas) o Realidad (Roma) nos proporcionan también textos e informaciones útiles para nuestro trabajo, que voy a reducir a partir de ahora al ámbito escénico entre 1939 y 1949.

\section{Teatro y exilio republicano}

El interés de la escena soviética por el teatro español, fundamentalmente el clásico (Lope de Vega, Calderón) pero también el contemporáneo (ValleInclán, García Lorca), es permanente y anterior a 1939. En rigor, el funcionamiento en 1944 de una "Comisión para el estudio del teatro español y latinoamericano", dirigida por Fédor Kelin y vinculada a la "Sociedad

20 "El 60 aniversario de Rafael Alberti en la URSS". España Popular, 930 (1 de marzo de 1963), p. 2. Al poeta comunista del exilio español se le concedió el Premio Lenin de la Paz, premio del que se informa en dicha revista en los números 957 (15 de mayo de 1965), p. 2, y 958 (30 de junio de 1965), p. 3 y 7.

${ }^{21}$ Entre sus traducciones más importantes recordemos desde la de Peribáñez y el comendador de Ocaña, de Lope de Vega (K. Grigoriev, "La cultura española en la URSS", España Popular, 302 (12 de julio de 1946), p. 4) a las del Amor de don Perlimplín con Belisa en su jardín, Yerma, Doña Rosita la soltera o Mariana Pineda, de García Lorca (Alexander Rusin, "El estudio del teatro español", España Popular, 190 (19 de mayo de 1944), p. 2).

22 "Los emigrados españoles en la URSS se dirigen a la Conferencia pro-Amnistía". España Popular, 905 (1 de mayo de 1961), p. 5. 
teatral de toda la Unión ${ }^{23 ", ~ a s i ́ ~ c o m o ~ l a ~ r e u n i o ́ n ~ c e l e b r a d a ~ p o r ~ " l a ~ S o c i e d a d ~}$ Teatral de Rusia y la Agrupación de Artistas Soviéticos" sobre la literatura dramática española ${ }^{24}$, constituyen pruebas objetivas de dicho interés. Ahora bien, la organización teatral soviética, que no se regía en absoluto por el mercantilismo artístico, fue la que realmente deslumbró al exilio republicano español, como refleja el siguiente comentario del crítico José Luis Salado : "El montaje de una comedia ocupa, a veces, meses enteros en un teatro soviético. Por ejemplo, El perro del hortelano - Lope de Vega en Moscú - tuvo ciento veinte ensayos antes de subir al escenario del Teatro de la Revolución ${ }^{25 "}$. Un hecho posible por la política de un Estado socialista que concebía la educación y la cultura como un servicio público a la mejor formación artística y política de unos ciudadanos soviéticos a quienes la literatura dramática española no les resultaba ajena. Prueba de ello, por ejemplo, la presencia simultánea de cuatro obras españolas en la cartelera teatral moscovita durante el mes abril de 1940 según testimonia el propio Salado, antiguo crítico teatral de la revista El Mono Azul durante la guerra civil : "Cuatro obras españolas hay esta semana en las carteleras teatrales de Moscú : El perro del hortelano, Fuenteovejuna, La dama invisible (sic) Calderón acaba de inaugurar un teatro soviético - y Bodas de sangre ${ }^{26}$. Y, en efecto, por una información posterior podemos verificar que El perro del hortelano, de Lope de Vega, se representó en el Teatro de la Revolución ; La dama duende, de Calderón, en el Teatro de la Comedia ; Marta la piadosa, de Tirso de Molina, desde "hace más de un año" en el Teatro Lensoviet ; La viuda de Valencia (sic), de Lope de Vega, en el Teatro de las Juventudes Comunistas y, finalmente, Bodas de sangre en el Teatro Romen (Gitano) de

23 "Incumbe a la Comisión ayudar también prácticamente a los teatros soviéticos en la elección de su repertorio español, así como la consulta durante la puesta en escena de piezas de dramaturgos españoles", según Alexander Rusin en "El estudio del teatro español". España Popular, 190 (19 de mayo de 1944), p. 2.

24 En dicha reunión se escucharon tres informes: los de Fédor Kelin ("Las dos Españas, la antifascista y la franquista"), Alexander Fevralsky ("Los lazos del teatro ruso y español") y Vladimir Uzin ("La dramaturgia española y el teatro soviético"), según se nos informa en "Reunión sobre literatura española". España Popular, 235 (6 de abril de 1945), p. 5.

25 José Luis Salado, "Escenarios de Moscú". España Popular, 13 (9 de mayo de 1940), p. 7.

26 José Luis Salado, "Lorca, otra vez entre los gitanos". España Popular, 11 (25 de abril de 1940), p. 7. 
Moscú ${ }^{27}$, en donde a continuación se puso en escena La zapaterita (sic) prodigiosa, también de García Lorca. Esta última puesta en escena nos interesa prioritariamente porque en ella intervino como escenógrafo un exiliado republicano español, el escultor Alberto Sánchez :

Es el artista español, Alberto Sánchez, hoy residente en Moscú, quien ha administrado ese aire andaluz a $L a$ zapaterita. Al espectador moscovita podrá parecerle su decorado un encanto de gracia y de color - sí que se lo parece - ; pero, para el espectador español, el rincón andaluz que Alberto Sánchez ha improvisado en el Teatro Gitano, con sus losas coloreadas, con sus cobres brillantes al sol, con sus litografias descoloridas de viejos fastos taurinos, le sabe a lo mejor de España. $Y$ no es un espejismo de la nostalgia porque se trata verdaderamente de España a miles y miles de kilómetros: la fragancia de España, la luz de España, las campanas de España ${ }^{28}$.

La colaboración escénica entre las compañías teatrales soviéticas y nuestro exilio republicano de 1939 nos aproxima a las trayectorias de dos

27 José Luis Salado, "La cultura española en la URSS". España Popular, 61 (4 de julio de $1941)$, p. 2. Tanto El perro del hortelano como La viuda valenciana "han sido traducidas al ucraniano, al bielorruso, al georgiano, al armenio, al tadjik y al turkmeno y actualmente figuran permanentemente en el repertorio de los teatros de casi todas las Repúblicas nacionales", según se precisa en "Reunión sobre literatura española". España Popular, 235 (6 de abril de 1945), p. 5.

${ }^{28}$ J. L. Salado, ob. cit., p. 2. 
importantes personalidades artísticas : el escultor Alberto $^{29}$ y el escritor César Arconada ${ }^{30}$.

César M. Arconada, escritor que se había iniciado en las vanguardias literarias de los años veinte y que fue secretario de La Gaceta Literaria ${ }^{31}$, era autor de una obra crítica $^{32}$ y de creación - narrativa, poesía y teatro - ya importante antes de 1939, como prueban novelas como Los pobres contra los ricos, Reparto de tierras ${ }^{33}$ o Rio Tajo ${ }^{34}$, publicadas en 1933, 1934 y 1938, respectivamente. Tras una breve estancia en el campo de

29 Algunas escenografías de Alberto en la escena soviética se reproducen en Alberto. Madrid, Ministerio de Cultura, 1980, p. 25 (La casa de Bernardo Alba), p. 30 (Mariana Pineda), p. 43 (La gitanilla, de Cervantes), p. 49 (La dama boba y Fuenteovejuna), p. 51 (Mariana Pineda) y p. 52-53 (La casa de Bernarda Alba). Quince años después también en Toledo se organizó una exposición de su obra, en cuyo catálogo, titulado Alberto. Encuentro en Toledo, 1895-1995 (Toledo, Ayuntamiento de Toledo, 1995) se reproduce también su escenografía para Mariana Pineda (p. 40).

${ }^{30}$ A lberto como escenógrafo y Arconada como autor de la adaptación escénica colaboraron en La gitanilla, de Cervantes, puesta en escena por el Teatro Gitano de Moscú en 19391941, según documenta Angel Martínez Roger en " El Alberto Sánchez escenógrafo », artículo publicado en la revista $A D E, 47$ (noviembre de 1995), p. 94-101, en donde se valoran veinti-cuatro trabajos suyos, dieciscis realizados ya en su exilio moscovita.

${ }^{31}$ La pionera de los estudios sobre la obra narrativa de Arconada fue Brigitte Magnien, autora de "La obra de César María Arconada, de la "deshumanización" al compromiso. La novela rural bajo la Segunda República", en el colectivo Sociedad, política y cultura en la España de los siglos XIX y XX. Madrid, Edicusa, 1973, p. 333-347, con prólogo de Manuel Tuñón de Lara. Sin embargo, es de justicia resaltar también la contribución de Gonzalo Santonja con su trabajo sobre "César M. Arconada. Bio-bibliografia", aparecido en la revista palentina Publicaciones de la Institución Tello Téllez de Meneses, 47 (1982), p. 5-57. En esta misma revista vio la luz el artículo de César Augusto Ayuso titulado "César $\mathrm{M}$. Arconada: vida y obra", 48 (1983), p. 211-236.

32 Sobre el tema puede consultarse la Obra periodística. De Astudillo a Moscú, de Arconada, edición y estudio introductorio de Christopher H. Cobb. Valladolid, Ediciones Ámbito, 1986.

${ }^{33}$ César M. Arconada, Reparto de tierras, edición y estudio preliminar de Gregorio Torres Nebrera. Badajoz-Palencia, Diputación Provincial de Badajoz, colección Raíces-7, 1988.

${ }^{34}$ La editorial Progreso de Moscú publicó en dos tomos las Obras escogidas de Arconada: en el primero se recditan sus novelas Los pobres contra los ricos (1933) y Reparto de tierras (1934), mientras que en el segundo se hace lo propio con Rio Tajo (1938). 
concentración francés de Argelès ${ }^{35}$, Arconada prosiguió en la URSS su obra de creación y de crítica $^{36} \mathrm{y}$, como director de la revista Literatura internacional - más tarde Literatura soviética -, se convirtió en un cualificado traductor ${ }^{37}$ y en un valioso interlocutor del hispanismo soviético.

En 1942 encabezó junto a Fédor Kelin la revista soviética en castellano La literatura internacional (más tarde, Literatura Soviética). Hacía falta mucha pureza humana, mucha serenidad y mucha fe en la victoria de la causa justa de nuestro pueblo y de todos los pueblos del mundo para, en plena guerra, propagar más allá de las fronteras de nuestro país la perenne sabiduría de la literatura clásica rusa y el espíritu combativo e indoblegable de la literatura soviética. En traducción de Kelin y Arconada, a los que unía una amistad de toda la vida, forjada aún en la guerra de España, fueron hacia miles de lectores de los países de habla española el célebre poema épico del pueblo ruso El cantar de las huestes de Igor, versos de nuestro Pushkin, la lírica civil de los revolucionarios decembristas, la cantarina y popular musa de Nekrásov, el austero romanticismo de Lérmontov, el vendaval de Blok, el clamor de Maiakovski, el canto al pueblo de Tvardovski.

Arconada fue también, con Fédor Kelin, padre de la escuela soviética de traducción de literatura amena del ruso al español (escuela que nació en gran parte alrededor de la revista), ganándose con ello el profundo respeto y el amor de sus numerosos discípulos ${ }^{38}$, pero no olvidemos tampoco ni su

35 "Fue con el libro de Cervantes debajo del brazo como atravesó Arconada las fronteras de nuestro país en el año 1939, cuando España quedó en manos del franquismo. Este libro le sirvió de almohada en el campo de concentración francés y nunca luego quiso separarse de él...", afirma Inna Tiniánova en "Evocación preliminar (a guisa de prólogo)" al primer tomo de las Obras escogidas de Arconada. Moscú, Progreso, s. f., p. 14.

${ }^{36}$ César M. Arconada, "Galdós y su época". Romance, México, 9 (1 de junio de 1940), p. 3-4, y 10 ( 15 de junio de 1940), p. 8 y 14.

37 "La famosa comedia La desgracia de tener talento, acaba de ser traducida por Fédor Kelin, en colaboración con el escritor español César Arconada", de la lengua rusa a la española se informa en "Reunión sobre literatura española". España Popular, 235 (6 de abril de 1945), p. 5.

38 I. Tiniánova, ob. cit., p. 14-15. Por su parte, Teresa Pàmies resalta también esa labor traductora de Arconada: "Por él conocemos a Sergei Orlov, a Nikolai Gribachov, al contestatario Vosnesenski y a tantos otros viejos y nuevos poetas de la URSS", escribe en Los que se fueron. Barcelona, Ediciones Martínez Roca, 1976, p. 69. 
trabajo como "escenificador" ${ }^{39}$ ni la escritura de una obra literaria en donde tanto la narrativa como la poesía fecundaron en publicaciones varias :

Desde 1939, reside en Moscú el escritor César M. Arconada.

Durante su estancia en la Unión Soviética, ha creado diversas obras de evidente interés; entre las que deben citarse, dos recapitulaciones de relatos tituladas España Invencible y Cuentos de Madrid, y una serie de hermosas composiciones poćticas : Stalin, Leningrado, Salud, Moscú ! y El Ejército Rojo. Todas ellas se han traducido al ruso y entre los lectores soviéticos han alcanzado lisonjero éxito.

Actualmente, César M. Arconada está escribiendo la segunda parte de su libro El (sic) Rio Tajo, que todavía no se ha publicado en español. Una traducción al ruso de la primera parte de esa obra apareció, también con gran éxito, en Moscú, antes de la guerra. La acción de El rio Tajo transcurre durante la lucha del pueblo español contra las fuerzas de la reacción mundial. Según la idea original del autor, El Rio Tajo debe tener tres partes. La segunda es la que, como hemos dicho, trabaja actualmente Arconada, se refiere a la suerte que corren los protagonistas del libro, después de la victoria provisional de Franco ${ }^{40}$.

Pero la obra de creación de Arconada incluye también varias obras dramáticas inéditas, entre las cuales Manuela Sánchez fue traducida a la lengua rusa y estrenada en 1952 en un teatro de la capital soviética :

En la Unión Soviética trabajó mucho. Tenía la práctica de sus Romances de guerra, consagrados a la guerra nacional revolucionaria del pueblo español, y escribió varias poesías dedicadas a la Gran Guerra Patria del pueblo soviético. Tenía la práctica de su farsa grotesca La conquista de Madrid, escrita en 1937, y compuso varias obras dramáticas, entre las cuales es de destacar el drama Manuela Sánchez, sobre esta heroína del movimiento guerrillero de España. Logró crear en

39 "También en estas reuniones se leyeron las traducciones al ruso de la comedia de Leandro Fernández de Moratín El si de las niñas, y de la comedia La molinera, escenificación de la conocida novela de Pedro Antonio de Alarcón El sombrero de tres picos. La escenificación corrió a cargo del escritor español César M. Arconada", en Alexander Rusin, "El estudio del teatro español". España Popular, 190 (19 de mayo de 1944), p. 2.

40 K. Grigoriev, "La cultura española en la URSS". España Popular, 302 (12 de julio de 1946), p. 4. 
esta obra un carácter de mucha entereza, de mucha fuerza popular y de mucha poesía también, un papel para Margarita Xirgu, que vimos aquí interpretado por la insigne actriz rusa Alisa Koonen en 1952, cuando la obra se puso en escena en la traducción de Fédor Kelin, traducción tan fiel al alma del pueblo español, y al mismo tiempo tan impregnada del alma del pueblo ruso.

Aquí creó Arconada su gran poema Dolores, sus Cuentos de Madrid y su libro de cuentos España es invencible ${ }^{41}$.

\section{El Club Español de Moscú}

Pero al margen de las actividades impulsadas por el hispanismo soviético - como, por ejemplo, traducciones ${ }^{42} \mathrm{o}$ actos en torno al centenario de Cervantes en $1947^{43}$-, el hecho más importante para el estudio del teatro, literatura y cultura del exilio republicano español de 1939 en la URSS fue, sin duda, la creación en 1946, tras la victoria aliada en la segunda guerra mundial, de un Club Español en Moscú, cuya historia se reconstruye sucintamente en una crónica de 1958 :

En 1946 se puso a disposición de los exiliados españoles que residen en Moscú el Club Chlakov, enclavado en las proximidades de la avenida de Leningrado, quizás la más hermosa de la capital de la URSS.

Desde hace 12 años, los emigrados despliegan en dicho club una gran actividad cultural, artística y recreativa, que

${ }^{41}$ I. Tiniánova, ob. cit., p. 14. Alcaén Sánchez, hijo del escultor Alberto, me precisa en carta fechada en Madrid el 19 de enero de 1998 algunas informaciones que públicamente le agradezco: por ejemplo, que "Alisa Coonen" era la "primera actriz del Teatro de Cámara de Moscú y esposa de Tairov" o que Manuela Sánchez, de Arconada, fue puesta en escena por el círculo de aficionados del club Chkalov de Moscú, cuyo asesoramiento escenográfico corrió a cuenta de mi padre".

42 "Antonio Machado en lengua rusa" y "Actividades hispanistas en la URSS", artículos ambos publicados en el Boletin de la Unión de Intelectuales Españoles, París, 18 (mayo de 1946), p. 12, y 38-39 (enero-febrero de 1948), p. 12.

43 "Cervantes y Lope de Vega en Moscú" y un artículo de Fédor Kelin titulado "Gorki y Cervantes", publicados ambos en Independencia, París, 6 (30 de abril de 1947), p. 2, y 7 (31 de mayo de 1947), p. 8. 
mantiene vivo y presente en los españoles el tesoro del arte nacional.

El club tiene una hermosa sala de espectáculos con 550 localidades, biblioteca y biblioteca infantil, sala de lectura, de exposiciones, de ajedrez, estudio de artes plásticas y unas 15 salas más para los ensayos de los diversos círculos de aficionados (de ópera y ballet, de danzas populares, de orquesta, de canto, de coros, dramáticos, de bailes...).

La asistencia a los espectáculos que se presentan, así como a la proyección de películas y a los distintos actos que se celebran, son completamente gratis.

La actividad que desarrollan los exiliados es muy variada, por lo que destacamos lo más representativo. Han sido montadas varias exposiciones (en 1947, 48, 52 y 56) con motivo del aniversario de la llegada de los niños españoles a la URSS en 1937 o con ocasión de otras efemérides. En dichas exposiciones se exhibieron primorosas labores, dibujos, pinturas, esculturas, diversos trabajos artísticos, colecciones de periódicos murales, máquinas en miniatura, etc. La contemplación de tantísimos trabajos, muchos de ellos muy valiosos, demuestran a qué grado ha llegado el cultivo del arte $y$ de los trabajos finos entre los emigrados, sobre todo entre los jóvenes, cuya mayoría al llegar aquí no sentían todavía inclinaciones o vocación definidas.

Se han organizado concursos literarios en los que han tomado parte numerosos prosistas y poetas, con notables dotes unos, sin madurar otros y en agraz los terceros, mas en los trabajos de todos ellos, diversos por su forma y contenido, ha vibrado el sentimiento patriótico, la añoranza de aquella España mártir, lejana y próxima a la vez.

Con ocasión de los aniversarios se han celebrado solemnes veladas dedicadas a hombres preclaros de España : Miguel Servet y Goya, Cervantes y Quevedo, Pedro Antonio de Alarcón y Valle-Inclán...

Cada verano tiene lugar una fiesta ya tradicional $y$ conmovedora : la dedicada a la terminación de la carrera. $\mathrm{Ha}$ habido años en que los homenajeados han llegado a 150.

Dos veces al mes, por lo menos, se celebran veladas artísticas. Además de la proyección de películas, se ponen en escena obras del repertorio del conjunto artístico, que en su actividad a lo largo de estos años ha logrado un elevado grado de maestría. 
El cuadro artístico ha conquistado merecida reputación. Integrado por estudiantes, obreros e intelectuales, ha representado El alcalde de Zalamea, de Calderón; Los melindres de Belisa y La dama boba, de Lope de Vega ; La verbena de la Paloma, de Bretón; El sombrero de tres picos, de Alarcón; Es mi hombre, de Arniches ; El retablo de las maravillas, de Cervantes ; En un lugar de España y Manuela Sánchez, de Arconada, y una infinidad de obras en un acto acerca de la vida en España.

Se han montado preciosos cuadros regionales (vasco, andaluz, aragonés, catalán y gallego), con abundantes números folklóricos, interpretados con profundo sentimiento y elevada maestría.

Los distintos conjuntos del club se han renovado en los últimos tiempos en buena medida.

Violeta González era ya aficionada al baile en su niñez, en sus tiempos de educanda en la casa de niños. Hacia 1948 se graduó en la Academia Timiriásev y, sin abandonar su cargo de ingeniero agrónomo, ingresó en la facultad de ballet del Instituto de teatro Lunatcharski. Terminó brillantemente sus estudios en 1955 y desde entonces, además de su actividad profesional con arreglo a su nueva especialidad, es profesora de bailes del conjunto español.

Mario Gómez, músico muy capaz, cursó con gran aprovechamiento en el Conservatorio de Moscú y al graduarse fue destinado al Palacio de la Cultura de la Fábrica de automóviles Lijachov, donde ejerce como prof (esor) de música y director de la orquesta de la misma. Es un gran conocedor de la música española. Gómez no ha olvidado a sus antiguos compañeros del club, ya que en la actualidad dirige la orquesta del mismo, integrada toda ella por españoles. 


\begin{abstract}
Merece señalarse que nuestros aficionados, que bien pudieran ser profesionales por su preparación, son requeridos por infinidad de clubs y casa de cultura soviéticos para actuar en sus veladas, en las que indefectiblemente alcanzan notables éxitos. De esta forma corresponden en cierta medida a aquellos que les abrieron todos los caminos de la vida y les ayudaron a hacerse hombres de provecho y patriotas cultos y auténticos. Corresponsal $^{44}$.
\end{abstract}

Además de la bailarina Violeta González y del músico Mario Gómez sin olvidar a Josefina Iturrarán, estrella indiscutible de La verbena de la Paloma y que actualmente sigue residiendo en Moscú -, el escritor César Arconada es el único dramaturgo del exilio republicano que fue estrenado por el Club Español de Moscú, al que alude en su crónica este "corresponsal" que, casi con toda seguridad, debe ser Amadeo Usón, según puede comprobarse a través de una carta dirigida a Rafael de Buen por este exiliado republicano en Moscú, que documenta la vinculación entre la organización mexicana y algunos intelectuales españoles en la URSS :

Sr. D. Rafael de Buen

UNIÓN DE INTELECTUALES ESPAÑOLES EN
MÉXICO

Estimado compatriota : A su debido tiempo llegó a mi poder su atenta carta del 20 de septiembre - que me dirige en nombre de la Unión de Intelectuales - y el Boletin que edita la citada organización. Considero que todo esfuerzo tendente a lograr los objetivos que se traza la Unión debe ser secundado por cuantos intelectuales se sienten conscientes de su deber patriótico, máxime en estas horas tan esperanzadoras y llenas a la vez de responsabilidad. A este fin se impone la unidad más estrecha entre todos los españoles como instrumento para acabar con el bochornoso régimen que sojuzga España. Convencido de tal sentimiento, no creo tenga derecho a rechazar el ofrecimiento que me hacen para que los represente en la Unión Soviética. Aportaré a esta labor mi entusiasmo y mejores afanes al objeto de colaborar lo más eficientemente posible en las actividades de la Unión y conseguir que los intelectuales españoles que residen en ésta, conozcan la

\footnotetext{
44 "Noticias de la URSS. Un Club Español en Moscú". Boletín de Información de la Unión de Intelectuales Españoles, México, 6 (julio de 1958), p. 27-28.
} 
actividad de esa organización y sean útiles a la misma. Pueden pedirme cuanto les sea necesario, en la seguridad de que serán atendidos en la medida en que pueda servirles. Si disponen de mayor cantidad de Boletines, les agradeceríamos nos enviaran unos cuantos más para repartirlos entre los compañeros. Y a propósito de esa publicación, quisiera manifestarles que la opinión general de cuantos la hemos leído es buena, y la consideramos viva e interesante. Tenemos interés en conocer el libro de G. Narezo y las conferencias de Max Aub sobre poesía. Les saluda muy cordialmente su compatriota.

\section{Amadeo Usón}

Moscú, noviembre 6, $1956^{45}$.

Manuela Sánchez, de Arconada, es una obra dramática sobre la personalidad de una campesina gallega que fue asesinada por la guardia civil al haber ayudado a la guerrilla, una campesina gallega que se convirtió en un mito de la resistencia popular contra la dictadura franquista ${ }^{46}$. Reeditar esta obra teatral y toda la creación literaria escrita por Arconada en su exilio soviético, libros como España es invencible (1941), Cuentos de Madrid (1942), Dolores (1945) o Teatro español en la escuela (1953), volumen este último que "forma parte de esa labor de adaptación de clásicos españoles con finalidades docentes ${ }^{47 \text { "; }}$ reconstruir con rigor documental la historia de las actividades del Club Español de Moscú a partir de 1946 ; en definitiva, recuperar la historia del teatro, la literatura y cultura del exilio republicano español de 1939 en la antigua Unión Soviética, constituyen otras tantas asignaturas pendientes de nuestra investigación, un tema al que, con el presente trabajo, sólo hemos pretendido una primera aproximación.

45 "Carta de Moscú". Boletín de Información de la Unión de Intelectuales Españoles, México, 3-4 (febrero-mayo de 1957), p. 32.

46 Juan Miguel Romá es autor de un poema "A Manuela Sánchez", publicado en Nuestro Tiempo, 2 (1 de octubre de 1951), p. 45.

${ }^{47}$ G. Torres Nebrera, "Estudio preliminar" a Reparto de tierras, de César Arconada, ob. cit., p. 26 , nota 19 . 